\title{
Evaluation of thallium-201 exercise scintigraphy in coronary heart disease
}

\author{
R. G. MURRAY, J. H. MCKILLOP, R. G. BESSENT, J. G. TURNER, \\ A. R. LORIMER, I. HUTTON, W. R. GREIG, AND T. D. V. LAWRIE \\ From University Departments of Medical Cardiology and Medicine, and Department of Nuclear Medicine, \\ Glasgow Royal Infirmary, Glasgow
}

SUMMARY Thallium-201 myocardial imaging provides a non-invasive technique in the investigation of patients with suspected coronary heart disease. This study was designed to evaluate thallium-201 $\left.{ }^{201} \mathrm{Tl}\right)$ scintigraphy in predicting the presence or absence of coronary heart disease in 50 patients presenting with chest pain.

${ }^{201} \mathrm{Tl}$ scintiscans were obtained in 4 projections at rest and on symptom-limited maximal exercise. The presence or absence of regional perfusion abnormality was determined by semiquantitative computer analysis. The results were compared with resting and exercise electrocardiography and the final diagnosis established by coronary arteriography.

In 33 patients with significant coronary artery disease, perfusion defects were present at rest in 13 $(39 \%)$ and on exercise in $30(91 \%)$. Exercise ${ }^{201} \mathrm{Tl}$ scintigraphy was significantly more sensitive in detecting the presence of coronary artery disease than resting scintigraphy. In 17 patients with normal coronary vessels, ${ }^{201} \mathrm{Tl}$ scans were normal in 15 at rest and 14 on exercise.

In 33 patients with coronary artery disease the electrocardiogram at rest and/or exercise was abnormal in $25(76 \%)$. The combination of exercise ${ }^{201} \mathrm{Tl}$ scintigraphy and exercise electrocardiography identified all 33 patients subsequently shown to have significant coronary artery disease.

Seventy-one vessels in 33 patients were diseased. All regions with relative perfusion abnormality were supplied by diseased vessels. However, 21 of 71 diseased vessels (31\%) were not associated with perfusion defects. This occurred only in patients with $\geqslant 2$ vessel disease.

These results suggest that computer analysed ${ }^{201} \mathrm{Tl}$ exercise scintigraphy is a valuable technique for identifying patients with significant coronary artery disease. ${ }^{201} \mathrm{Tl}$ image data were highly sensitive for detecting the presence of coronary artery disease though accuracy in predicting the extent of disease was limited in patients with multiple vessel disease. These data provide further justification for the use of exercise ${ }^{201} \mathrm{Tl}$ scintigraphy especially in conjunction with exercise electrocardiography in the investigation of patients with chest pain.

Exercise testing has an established place in the investigation of patients with suspected coronary heart disease. However, the electrocardiographic response to exercise has limited diagnostic accuracy (Mason et al., 1967; Kassebaum et al., 1968; Roitman et al., 1970; Blomqvist, 1971; Friesinger and Smith, 1972; Martin and McConahay, 1972; Borer et al., 1975).

Myocardial imaging after the intravenous injection of thallium-201 (201Tl) provides a noninvasive assessment of myocardial perfusion (Strauss

Received for publication 4 September 1978 et al., 1975) and can be used to detect myocardial infarction (Wackers et al., 1975; Parkey et al., 1976; Hamilton et al., 1977; Henning et al., 1977; Wackers et al., 1977) and stress-induced ischaemia (Bailey et al., 1977; Lenaers et al., 1977; McLaughlin et al., 1977; Ritchie et al., 1977; Rosenblatt et al., 1977).

This study was designed to evaluate ${ }^{201} \mathrm{Tl}$ scintigraphy in predicting the presence or absence of coronary artery disease in patients presenting with chest pain. ${ }^{201} \mathrm{Tl}$ scintiscans were obtained at rest and after maximal exercise testing and the results compared with selective coronary arteriography. 


\section{Patients and methods}

Fifty patients being investigated for suspected coronary artery disease were studied. Forty-six patients were men and 4 were women, mean age 46.7 years \pm 1.13 (mean \pm SEM) range 27 to 57 years. ${ }^{201} \mathrm{Tl}$ scintiscans were obtained at rest and after exercise testing, with an interval of at least 5 days between rest and exercise studies. Both rest and exercise studies were performed within 14 days of coronary arteriography. The experimental nature of the study was explained and informed consent obtained.

\section{RADIONUCLIDE STUDIES}

Thallium-201 scintiscans were obtained at rest and after symptom limited maximal exercise testing.

\section{EXERCISE TESTING}

Continous multistage exercise was performed using a graded bicycle ergometer with initial workload of $300 \mathrm{kpm} / \mathrm{min}$ and increments of 300 $\mathrm{kpm} / \mathrm{min}$ at 3-minute intervals. The electrocardiogram (modified V5 electrode) was monitored continuously with sampling at 3-minute intervals and at the end-point of exercise. The tests were discontinued because of chest pain $(94 \%)$ or dyspnoea/fatigue $(6 \%)$. Electrocardiographic monitoring and intermittent sampling was continued up to 12 minutes after exercise.

The exercise electrocardiogram was interpreted independently without knowledge of ${ }^{201} \mathrm{Tl}$ scintiscan or arteriogram results. The test was considered positive for the presence of coronary artery disease where there was horizontal or downsloping ST depression more than or equal to $1 \mathrm{~mm}$ during or after exercise.

In addition to the results of exercise electrocardiography, the presence of a previous myocardial infarction in the resting electrocardiogram, irrespective of the exercise electrocardiographic appearance, was considered to indicate the presence of coronary artery disease.

\section{MYOCARDIAL IMAGING}

Scintiscans were obtained after the intravenous injection of $2 \mathrm{mCi}$ thallium-201 (thallous chloride, supplied by Duphar Laboratories). After a 4-hour fast, the rest injection was given in the upright position to minimise hepatic and gastric activity. The exercise injection was given at the onset of symptoms and exercise was terminated 30 seconds thereafter.

Myocardial imaging was performed using an Ohio Nuclear Series 100 Gamma Camera with a high resolution, medium sensitivity, parallel hole collimator. Scans were obtained in the anterior, $30^{\circ}$ and $60^{\circ}$ left anterior oblique, and left lateral projections. The gamma camera was interfaced to a Varian $620 \mathrm{~L}$ computer and the image data stored on magnetic tape for later retrieval. The images were analysed using a semiquantitative technique to examine regions of interest (McKillop et al., 1978; Murray et al., 1978). Using the light pen of the computer, regions of interest were generated on each myocardial image corresponding to the anatomical areas described by Lenaers $e t$ al. (1977). The total counts in each region and its area were calculated by the computer and thus count density (counts per unit area) for each region were obtained. In each image, the maximal count density was scored as 100 per cent and the count density in the remaining regions in the same image expressed as a percentage of this. A study of normal volunteer subjects (McKillop et al., 1978; Murray et al., 1978) had indicated that count densities for given anatomical areas varied by less than 15 per cent. Thus a variation of 20 per cent or more was accepted as indicating abnormal perfusion.

Loci of hypoperfusion were attributed to vessel disease according to the data of Lenaers et al. (1977). Thus perfusion defects in the anterior, anteroseptal, and anterolateral regions were interpreted as indicating disease of the left anterior descending coronary artery and defects in the posterolateral region as indicating disease of the left circumflex coronary artery. Since the size of supplying areas of the right and left circumflex coronary arteries is dependent on the type of coronary circulation (Kalbfleisch and Hort, 1977), perfusion defects in the inferior and posterior areas were interpreted as indicating right and/or left circumflex disease. Hypoperfusion in the posteroseptal region was interpreted as indicating disease of the left anterior descending and/or right coronary arteries. Significant perfusion defects of the apical segment were considered as indicating the presence of coronary artery disease but could not be attributed to disease of a particular coronary artery.

\section{CORONARY ARTERIOGRAPHY}

Selective coronary arteriography was performed by the percutaneous femoral route. Significant coronary artery disease was considered present in any vessel where the luminal diameter was reduced by 50 per cent or more in any of the standard projections. For the purposes of this study, the right coronary artery, main left coronary artery, left anterior descending, and left circumflex coronary arteries were analysed. Patients with coronary artery disease were classified as 


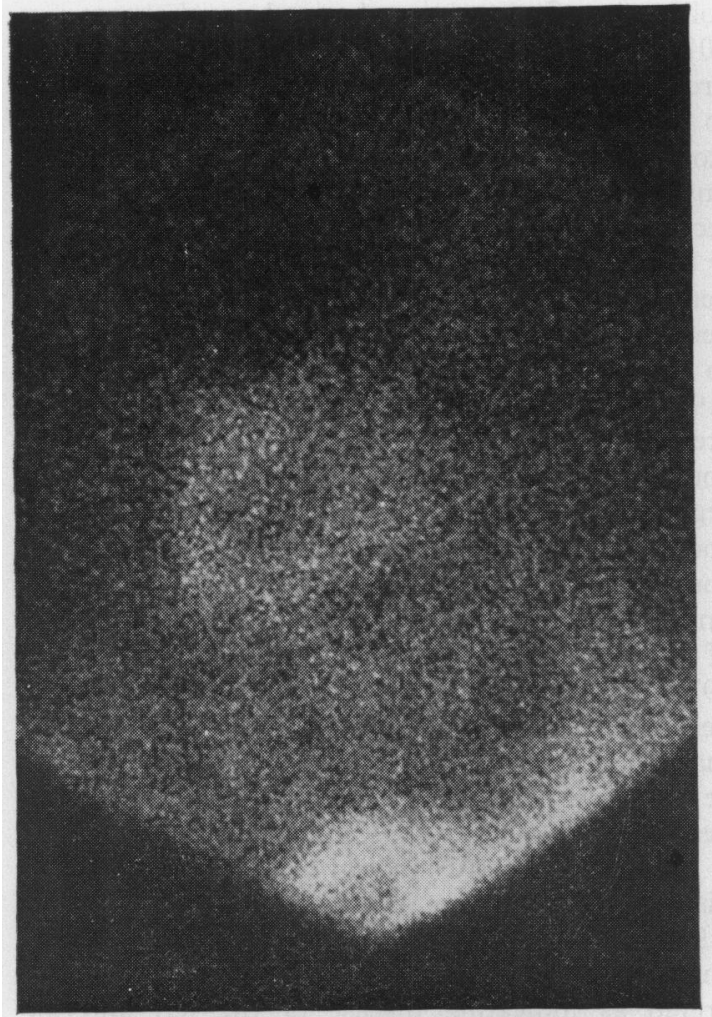

Fig. 1 Thallium-201 rest scintiscan taken in $60^{\circ}$ left anterior oblique projection in patient with normal left ventricular function and isolated left anterior descending artery disease. Nuclide density is equal in all areas in rest scan.

having single, double, or triple vessel disease according to the results of arteriography.

\section{Results}

\section{RADIONUCLIDE STUDIES}

Satisfactory scintiscans were obtained in all patients. Perfusion defects were present at rest in 15 patients and on exercise in 33 patients. In 10 of the 15 (67\%) patients with resting defects, the distribution of perfusion abnormality was more extensive after exercise.

Typical image data are represented in Fig. 1 and 2. These scans were obtained in the $60^{\circ}$ left anterior oblique projection in a patient with isolated left anterior descending artery disease and normal left ventricular function. Fig. 1 represents the rest scan and Fig. 2 represents the exercise scan. Nuclide density is equal in all areas in the rest scan; however, on exercise, a perfusion defect (arrowed) has developed in the anteroseptal and apical zones corresponding to left anterior descending artery disease.

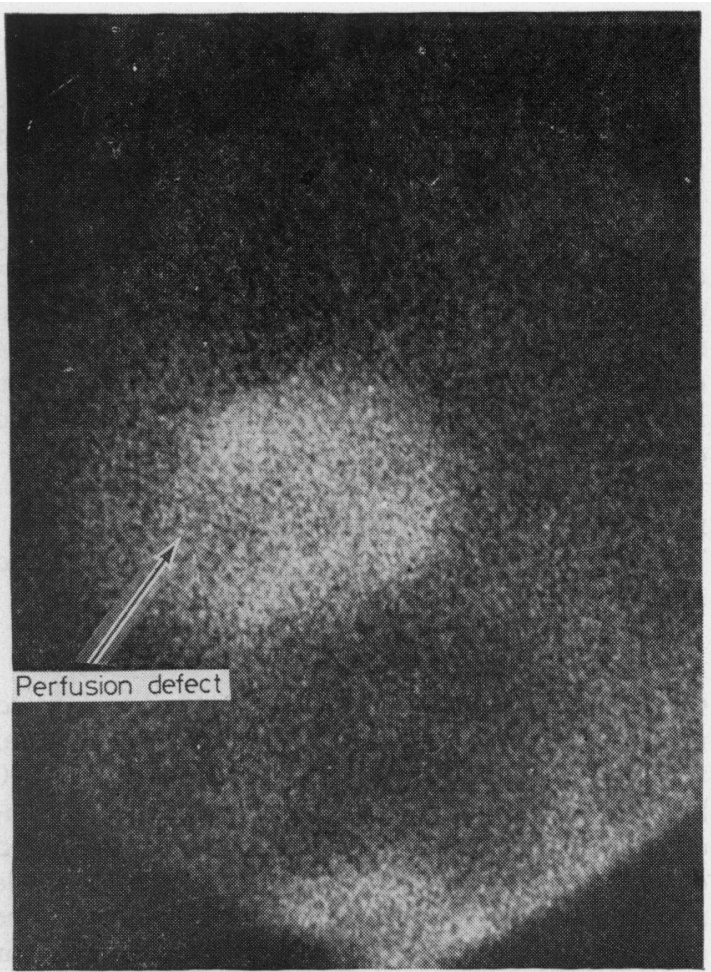

Fig. 2 Thallium-201 exercise scintiscan taken in $60^{\circ}$ left anterior oblique projection in same patient as Fig. 1. Note development of perfusion defect (arrowed) in anteroseptal and apical zones corresponding to left anterior descending artery disease.

\section{ANGIOGRAPHIC DATA}

Thirty-three patients had significant coronary artery disease, while 17 patients had normal vessels or minor $(<50 \%)$ disease. Six patients had single vessel disease ( 3 right coronary artery; 3 left anterior descending artery); 16 double vessel disease (9 right coronary artery + left anterior descending artery; 4 left anterior descending + left circumflex arteries; 3 right coronary + left circumflex arteries; and 11 had triple vessel disease (left anterior descending + right coronary artery + left circumflex artery). Left main and isolated left circumflex disease were not encountered.

\section{ELECTROCARDIOGRAPHIC DATA}

In 25 of the 33 patients with arteriographic coronary artery disease, the electrocardiogram either at rest ( 12 patients) or on exercise (13 patients) indicated coronary disease. In those 12 patients with evidence of previous myocardial infarction on the electrocardiogram, 8 were located anteriorly and 4 inferiorly. In 13 patients significant ST abnormality developed on exercise. 
Table Relation between scintigraphic findings and distribution of vessel disease in 33 patients with coronary artery disease

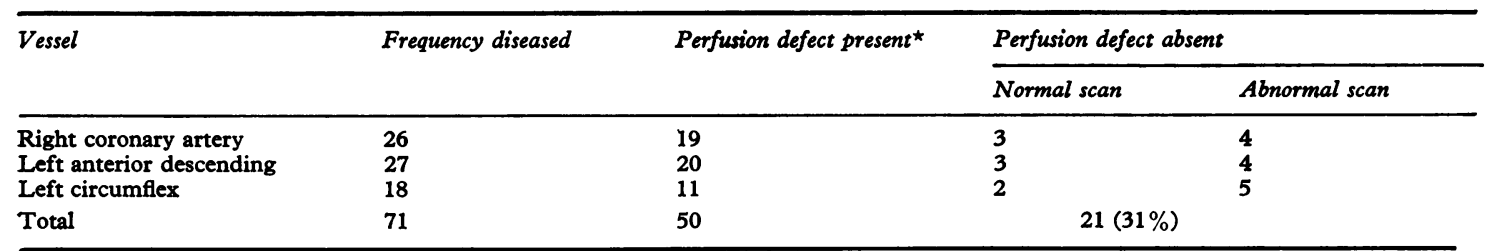

$\star$ Perfusion defect on exercise scintiscan.

COMPARISON OF DATA

In the 33 patients with significant coronary artery disease, perfusion defects were present in the rest ${ }^{201} \mathrm{Tl}$ studies in 13 patients $(39 \%)$ and in the exercise ${ }^{201} \mathrm{Tl}$ studies in 30 patients $(91 \%)$. Perfusion defects suggesting the presence of coronary artery disease were significantly more frequent in the exercise study than in the rest study ( 30 patients -exercise study; 13 patients-rest study; $P<0.05$ ). Three patients, 2 with triple vessel disease and 1 with double vessel disease (right coronary artery + left anterior descending artery), appeared to have normal ${ }^{201} \mathrm{Tl}$ studies at rest and exercise.

In the 17 patients with normal coronaries or minor disease, the ${ }^{201} \mathrm{Tl}$ scans were normal at rest in 15 and on exercise in 14. Two patients with normal coronary arteries had perfusion defects at rest, one of which persisted on exercise, and a further 2 patients developed perfusion defects on exercise. In 2 of these 3 patients with normal coronaries but abnormal exercise scintiscans the exercise electrocardiogram was also abnormal.

Six patients had single vessel disease, 16 had double vessel disease, and 11 triple vessel disease. The right coronary artery was involved in 26, left anterior descending in 27, and left circumflex in 18 instances. In 30 of the 33 patients with coronary artery disease, ${ }^{201} \mathrm{Tl}$ perfusion defects were present on exercise. In all instances, regions with relative underperfusion were supplied by diseased vessels. However, 21 of the $71(31 \%)$ diseased vessels were not associated with perfusion defects (Table). Exercise scintiscans were normal in 3 patients despite the presence of triple vessel disease in 2 and double vessel disease in 1 (right coronary artery + left anterior descending). In 10 of the 30 patients $(33 \%)$ with abnormal scintiscans and coronary artery disease, the distribution of perfusion abnormality underestimated the extent of disease. Eight of these patients had triple and 2 had double vessel disease. Thus, even where scintiscans were abnormal, 13 of 63 diseased vessels $(21 \%)$ were not associated with the development of perfusion defects on exercise (Table). Image data under- estimated left circumflex disease more frequently than right coronary artery and left anterior descending artery disease.

The electrocardiogram detected significant coronary artery disease in 25 of 33 patients (76\%) with coronary artery disease; 12 had evidence of previous myocardial infarction and 13 had positive exercise electrocardiograms. The exercise scintigram was abnormal in 91 per cent of patients with coronary artery disease. In all the 3 patients with normal scintiscans and coronary artery disease, the exercise electrocardiogram was positive. Thus, the combination of electrocardiography and exercise scintigraphy suggested the presence of coronary artery disease in all 33 patients subsequently shown to have significant disease (Fig. 3).

\section{Discussion}

Increasing emphasis is being placed upon noninvasive techniques to identify patients with significant coronary artery disease, and resting and exercise electrocardiography are useful in the

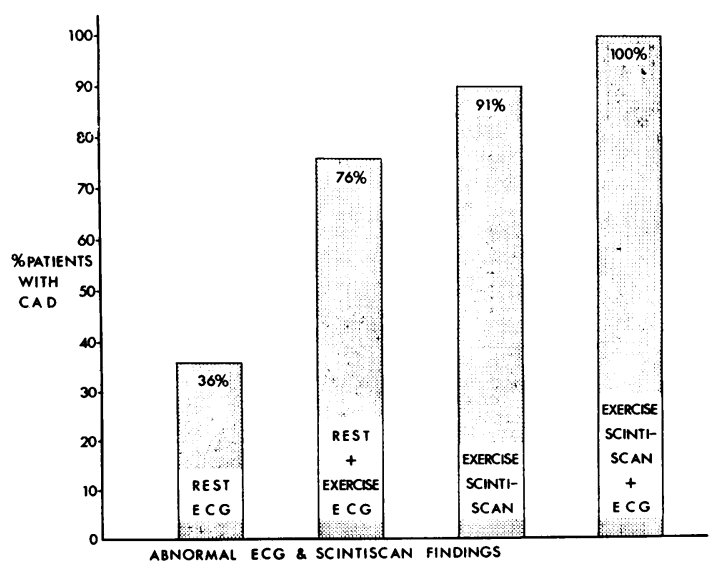

Fig. 3 Frequency of abnormal electrocardiogram and exercise scintiscan findings in 33 patients with arteriographically documented coronary artery disease. 
investigation of patients with chest pain. However, both the resting $Q$ wave (Horan et al., 1971; McGuiness et al., 1976) and exertional ST displacement (Mason et al., 1967; Kassebaum et al., 1968; Roitman et al., 1970; Blomqvist, 1971; Friesinger and Smith, 1972;Martin and McConahay, 1972; Borer et al., 1975) have limited accuracy in the detection of coronary artery disease. Lead selection may influence the performance of the exercise electrocardiogram. However, Blackburn (1969) showed that a modified V5 lead system was as accurate as the 12 lead electrocardiogram and the Frank XYZ leads in detecting exercise-induced ST segment displacement.

Myocardial imaging after the intravenous administration of radionuclide tracers provides a relatively non-invasive technique for estimating regional myocardial perfusion (Strauss et al., 1975). Of the currently available tracers, ${ }^{201} \mathrm{Tl}$ appears to be one of the most promising and ${ }^{201} \mathrm{Tl}$ scintigraphy is proving useful in detecting myocardial infarction (Wackers et al., 1975; Parkey et al., 1976; Hamilton et al., 1977; Henning et al., 1977) and stressinduced ischaemia (Bailey et al., 1977; Lenaers et al., 1977; McLaughlin et al., 1977; Ritchie et al., 1977; Rosenblatt et al., 1977).

This study shows that image data from ${ }^{201} \mathrm{Tl}$ exercise scintigraphy can be useful in predicting the presence or absence of coronary artery disease in patients presenting with chest pain. Abnormal image data were obtained in 30 of 33 patients $(91 \%)$ with documented coronary artery disease ( $\geqslant 50 \%$ stenoses). Only 3 patients with coronary artery disease had normal image data. There were no apparent features to identify those 3 patients with normal scintiscans ( 1 with double and 2 with triple vessel disease) from those in whom perfusion defects developed. The high sensitivity of myocardial imaging in this study $(91 \%)$ compared with other published data (Bailey et al., 1977; McLaughlin et al., 1977; Ritchie et al., 1977) may be, in part, related to the technique of analysis. The visual assessment of myocardial images is open to several criticisms. Interpretation may be complicated by a relatively poor target-background ratio. Non-homogeneity of tracer uptake by the myocardium, particularly in the region of the apex (Cook et al., 1976) may add further difficulties while the use of background subtraction and contrast enhancement techniques may serve to emphasise normal variations in tracer concentration rather than to disclose abnormal nuclide distribution. In addition, visual interpretation is subject to unintentional observer bias (Trobaugh et al., 1978), though this may be eliminated by independent reporting of the image data by 2 or more observers with a consensus being accepted. In an attempt to overcome some of these difficulties a semiquantitative approach using a regions of interest technique was employed in the analysis of the image data. Our earlier study of normal subjects had indicated that count densities calculated for given anatomical areas varied by less than 15 per cent. Thus, a variation of 20 per cent or more in any area was accepted as indicating abnormal perfusion. The locus of abnormality was related to vessel disease as suggested by Lenaers et al. (1977). In view of the reciprocal relation between the size of area supplied by the right and left circumflex coronary arteries depending on the type of coronary circulation (Kalbfleisch and Hort, 1977), it was felt justified in accepting abnormal perfusion in inferior and posterior segments as indicating disease of right and/or left circumflex vessels. The approach is not, however, wholly objective since it requires a selection of regions of interest by the observer with the attendant risk of interobserver variation and is only semiquantitative since count densities for any given anatomical area will be influenced to some extent by activity present in adjacent partially overlapping areas and by background activity.

Rest imaging was significantly less useful in detecting the presence of myocardial ischaemia than was the exercise data (exercise sensitivity $91 \%$; rest sensitivity $39 \% \mathrm{P}<0.05$ ). However, blood flow and regional distribution abnormalities caused by coronary stenoses of 50 per cent or more may only become apparent during exercise or pharmacological challenge (Gould et al., 1974a, b). Thus, since myocardial ${ }^{201} \mathrm{Tl}$ distribution parallels flow (Strauss et al., 1975), it might be expected that resting image data may not detect haemodynamically significant coronary disease.

The group of patients with normal coronary arteries or minor disease was small, predominantly male, and, since the presenting symptom in each was chest pain, cannot be classed as 'normal'. However, perfusion defects on ${ }^{201} \mathrm{Tl}$ exercise scintigraphy proved specific for the presence of coronary artery disease in all but 3 patients (specificity $82 \%$ ). Two of these patients also had an 'ischaemic' response to exercise on the electrocardiogram and may fall into the category of patients with angina but without arteriosclerotic coronary disease (Likoff et al., 1967; James, 1970; Waxler et al., 1971; Bemiller et al., 1973; Kemp et al., 1973).

The exercise ${ }^{201} \mathrm{Tl}$ scintigram could detect the presence of myocardial ischaemia and the location of perfusion defect corresponded to a diseased vessel. However, though accurate in detecting the presence of coronary artery disease in a given patient, 
this does not imply accuracy in predicting the extent of disease. A total of 31 per cent (21 of 71) diseased vessels were not associated with appropriate perfusion defects. This was encountered in 13 of the 33 patients with coronary artery disease, 10 of whom had triple vessel and 3 with double vessel disease. Several explanations can be proposed. A perfusion defect was defined by comparing regional tracer concentrations. The region with the highest count density was accepted as 'normal', but may well have been supplied by a vessel with significant luminal narrowing. This is particularly apposite in patients with multiple vessel disease. Further, the development of ischaemia in only one of a number of potentially ischaemic zones may have produced image data underestimating the extent of disease, while the contribution of coronary collateral circulation may have influenced the regional concentration of tracer. Circumflex disease was most frequently underestimated. This is possibly related to regional overlap in the scanning projections used. Only in the $60^{\circ}$ left anterior oblique projection is an isolated region (posterolateral) supplied by the left circumflex clearly visualised. However, it should be emphasised that the ${ }^{201} \mathrm{Tl}$ image data were highly sensitive $(91 \%)$ for detecting the presence of coronary artery disease despite the limited accuracy in predicting the extent of disease.

The combination of rest and exercise electrocardiography detected the presence of coronary artery disease in 76 per cent of patients with coronary artery disease. Exercise imaging compares favourably-91 per cent scintigram positive. However, sensitivity for the presence of coronary artery disease was 100 per cent when both the exercise scintigram and electrocardiogram were taken into account (Fig. 3).

These results suggest that computer analysed ${ }^{201} \mathrm{Tl}$ imaging was a useful additional technique in the investigation of patients with suspected coronary artery disease. Perfusion defects on the exercise scintigram were sensitive, but slightly less specific for the presence of coronary artery disease. These data provide further justification for the use of exercise ${ }^{201} \mathrm{Tl}$ scintigraphy especially in conjunction with exercise electrocardiography in the investigation of patients presenting with chest pain.

\section{References}

Bailey, I. K., Griffith, L. S. C., Rouleau, J., Strauss, H. W., and Pitt, B. (1977). Thallium-201 myocardial perfusion imaging at rest and during exercise. Comparative sensitivity to electrocardiography in coronary artery disease. Circulation, 55, 79-87.

Bemiller, C. R., Pepine, C. J., and Rogers, A. K. (1973).
Long-term observations in patients with angina and normal coronary arteriograms. Circulation, 47, 36-43.

Blackburn, H. (1969). Measurement in Exercise Electrocardiography. Charles C. Thomas, Springfield, Illinois.

Blomqvist, C. G. (1971). Use of exercise testing for diagnostic and functional evaluation of patients with arteriosclerotic heart disease. Circulation, 44, 1120-1136.

Borer, J. F., Brensike, J. F., Redwood, D. R., Itscoitz, S. B., Passamani, E. R., Stone, N. J., Richardson, J. M., Levy, R. I., and Epstein, S. E. (1975). Limitations of the electrocardiographic response to exercise in predicting coronary artery disease. New England fournal of Medicine, 293, 367-371.

Cook, D. J., Bailey, I., Strauss, H. W., Rouleau, J., Wagner, H. N., and Pitt, B. (1976). Thallium-201 for myocardial imaging: appearance of the normal heart. Fournal of Nuclear Medicine, 17, 583-589.

Friesinger, G. C., and Smith, R. F. (1972). Correlation of electrocardiographic studies and arteriographic findings with angina pectoris. Circulation, 46, 1173-1184.

Gould, K. L., Hamilton, G. W., Lipscomb, K., Ritchie, J. L., and Kennedy, J. W. (1974a). Method for assessing stress induced malperfusion during coronary arteriography. American fournal of Cardiology, 34, 557-564.

Gould, K. L., Lipscomb, K., and Hamilton, G. W. (1974b). Physiological basis for assessing critical coronary stenosis. American fournal of Cardiology, 33, 87-94.

Hamilton, G. W., Trobaugh, G. B., Ritchie, J. L., Williams, D. L., Weaver, W. D., and Gould, K. L. (1977). Myocardial imaging with intravenously injected thallium-201 in patients with suspected coronary artery disease: analysis of technique, and correlation with arteriographic, coronary anatomic and ventriculographic findings. American fournal of Cardiology, 39, 347-354.

Henning, H., Schelbert, H. R., Righetti, A., Ashburn, W. L., and O'Rourke, R. A. (1977). Dual myocardial imaging with technetium-99 m pyrophosphate and thallium-201 for detecting, localising and sizing acute myocardial infarction. American fournal of Cardiology, 40, 147-155.

Horan, L. G., Flowers, N. C., and Johnson, J. C. (1971). Significance of the diagnostic $Q$ wave of myocardial infarction. Circulation, 43, 428-436.

James, T. N. (1970). Angina without coronary disease (sic). Circulation, 42, 189-191.

Kalbfleisch, H., and Hort, W. (1977). Quantitative study on the size of coronary artery supplying areas post mortem. American Heart fournal, 94, 183-188.

Kassebaum, D. G., Sutherland, K. I., and Judkins, M. P. (1968). A comparison of hypoxemia and exercise electrocardiography in coronary artery disease: diagnostic precision of the methods correlated with coronary angiography. American Heart fournal, 75, 758-776.

Kemp, H. G., jun, Vokonas, P. S., Cohn, P. F., and Gorlin, R. (1973). The anginal syndrome associated with normal coronary arteriograms. American fournal of Medicine, 54, 735-742.

Lenaers, A., Block, P., Yan Thiel, E., Lebedelle, M., Becquevort, P., Erbsmann, F., and Ermans, A. M. (1977). Segmental analysis of T1-201 stress myocardial scintigraphy. fournal of Nuclear Medicine, 18, 509-516.

Likoff, W., Segal, B. L., and Kasparian, H. (1967). Paradox of normal selective coronary arteriograms in patients considered to have unmistakable coronary heart disease. New England fournal of Medicine, 276, 1063-1066.

McGuiness, J. B., Begg, T. B., and Semple, T. (1976). First electrocardiogram in recent myocardial infarction. British Medical fournal, 2, 449-451.

McKillop, J. H., Murray, R. G., Turner, J. G., Gray, H. W., Bessent, R., Lorimer, A. R., and Greig, W. R. (1978). Thallium-201 myocardial imaging in the detection of 
coronary artery disease; sensitivity and specificity. Radioactive isotope in Klinik und Forschung, 13, 257-264.

McLaughlin, P. R., Martin, R. P., Doherty, P., Daspit, S., Goris, M., Haskell, W., Lewis, S., Kriss, J. P., and Harrison, D. C. (1977). Reproducibility of thallium-201 myocardial imaging. Circulation, 55, 497-503.

Martin, C. M., and McConahay, D. R. (1972). Maximal treadmill exercise electrocardiography and cardiac hemodynamics. Circulation, 46, 956-962.

Mason, R. E., Likar, I., Biern, R. O., and Ross, R. S. (1967). Multiple lead exercise electrocardiography: experience in 107 normal subjects and 67 patients with angina pectoris, and comparison with coronary cinearteriography. Circulation, 36, 517-525.

Murray, R. G., McKillop, J. H., Bessent, R. G., Greig, W. R., and Lorimer, A. R. (1978). Thallium-201 exercise testing in coronary artery disease. Acta Medica Scandinavica, (S615) 77-84.

Parkey, R. W., Bonte, R. J., Stokely, E. M., Lewis, S. E., Graham, K. D., Buja, L. M., and Willerson, J. T. (1976). Acute myocardial infarction imaged with $99 \mathrm{~m}$ Tc-Stannous pyrophosphate and 201 Tc: a clinical evaluation. fournal of Nuclear Medicine, 17, 771-779.

Ritchie, J. L., Trobaugh, G. B., Hamilton, G. W., Gould, K. L., Narahara, K. A., Murray, J. A., and Williams, D. L. (1977). Myocardial imaging with thallium-201 at rest and during exercise: comparison with coronary arteriography and resting and stress electrocardiography. Circulation, 56, 66-71.

Roitman, D., Jones, W. B., and Sheffield, L. T. (1970). Comparison of submaximal exercise ECG test with coronary cineangiocardiogram. Annals of Internal Medicine, 72, 641-647.
Rosenblatt, A., Lowenstein, J. M., Kerth, W., and Handmaker, H. (1977). Post-exercise thallium-201 myocardial scanning: a clinical appraisal. American Heart fournal, 94, 463-470.

Strauss, H. W., Harrison, K., Langan, J. K., Lebowitz, E., and Pitt, B. (1975). Thallium-201 for myocardial imaging: relation of thallium-201 to regional myocardial perfusion. Circulation, 51, 641-645.

Trobaugh, G. B., Wackers, F. J. Th., Busemann Sokole, E., DeRouen, T. A., Ritchie, J. L., and Hamilton, G. W. (1978). Thallium-201 myocardial imaging: an interinstitutional study of observer variability. Fournal of Nuclear Medicine, 19, 359-363.

Wackers, F. J. Th., Becker, A. E., Samson, G. E., Busemann Sokole, E., van der Schoot, J. B., Vet, A. J. T., Lie, K. I., Durrer, D., and Wellens, H. (1977). Location and size of acute transmural myocardial infarction estimated from thallium-201 scintiscans: a clinicopathological study. Circulation, 56, 72-78.

Wackers, F. J. Th., v. d. Schoot, J. B., Busemann Sokole, E., Samson, G., van Niftrik, G. J. C., Lie, K. I., Durrer, D., and Wellens, H. J. J. (1975). Non-invasive visualisation of acute myocardial infarction in man with thallium-201. British Heart fournal, 37, 741-744.

Waxler, E. B., Kimbiris, D., and Dreifus, L. S. (1971), The fate of women with normal coronary arteriograms and chest pain resembling angina pectoris. American fournal of Cardiology, 28, 25-32.

Requests for reprints to Dr R. G. Murray, Department of Medical Cardiology, Royal Infirmary, Glasgow G4 0SF. 